\title{
Multi-period Model for Selection of Stakeholder Engagement Strategies of the Company
}

\author{
Aleksandr Aleksandrovich Gresko ${ }^{1} \&$ Konstantin Sergeevich Solodukhin ${ }^{1}$ \\ ${ }^{1}$ Vladivostok State University of Economics and Service, Russia \\ Correspondence: Aleksandr Aleksandrovich Gresko, Vladivostok State University of Economics and Service, \\ Gogol Street, 41, 690014, Vladivostok, Russia.
}

Received: November 1, 2014

Accepted: December 23, 2014 Online Published: March 16, 2015

doi:10.5539/ass.v11n7p190

URL: http://dx.doi.org/10.5539/ass.v11n7p190

\begin{abstract}
The present study proposes a multi-period model for selection of the most suitable types of engagement strategies of the company with different stakeholders in the context of uncertainty (risk). In the model considered a number of scenarios under which relationships of the company with the stakeholder groups vary periodically. For each scenario periodically predicted the dynamics of changes in the characteristics of such relations, and calculated weighing coefficients of applicability of the type of engagement strategy of the company with each stakeholder group. Coefficients obtained are reduced to integral coefficients based on which, using a generalized criterion that combines the expected value and the mean squared deviation, made the decision on the choice of a particular type of engagement strategies of the company with each stakeholder. This approach allows to select and rank the Pareto-optimal set of types of strategies and delimit the risk tolerance of the decision maker. The model also provides a method of selecting the most suitable type of strategy based on the expected utility criterion. The advantage of the proposed model is that it takes into account the risk tolerance of the decision-maker.
\end{abstract}

Keywords: multi-period model, stakeholders, stakeholder engagement strategies, generalized criterion, expected utility criterion, deterministic equivalent, risk tolerance

\section{Introduction}

The stakeholder concept (stakeholder theory), along with neoclassical and agency (shareholder) concept, is one of the three enterprise concepts in the developed economy (while the existence of a variety of other theories of the company (see, for example, (Foss et al., 1998; Kleiner, 2003a; Kleiner, 2008; Kleiner, 2003b; Tambovtsev, 2010; Dietrich \& Krafft, 2012).

The origin of the stakeholder theory dates back to the widely acknowledged and often cited work of Freeman, R.E. "Strategic Management: The concept of stakeholders" published in 1984, where the author introduced a new concept "a stakeholder", giving its definition, and proposed to consider the original model of the corporation (company) (Freeman, 1984).

According to the stakeholder concept the activities of the company depend on a wide variety of stakeholders (customers, suppliers, shareholders, managers, employees, and others), with each of the stakeholders having his her own interests and certain rights to the company control. The concept involves making decisions based on the need to meet multiple and frequently conflicting needs of these stakeholders (Kleiner, 1999).

An extremely important role in the development of the stakeholder concept belongs to the work of Post, J., Preston, L., \& Saks, S. (Post et al., 2002) which, in fact, summed up the five-year (1995-2000) project "Rethinking the Corporation", supported by the grant given by Sloan Fond, and laid the foundations for a "new stakeholder approach". According to the authors of this work, the modern corporation serves the center of a network of interconnected elements (stakeholders), each of which contributes (voluntarily or involuntarily) to the results of the company business activities and looks after hishher own interests (or at least the absence of uncompensated damage).

Strictly speaking, the stakeholder theory of the firm can be regarded as an independent direction in research of the general and strategic management. The stream of publications on relevant topics and content continued for 
about a quarter of the century indicates the theoretical and practical significance of this approach, and at the same time - its incompleteness and partial inconsistency (Tambovtsev, 2008b; Phillips, 2011).

The stakeholder engagement strategies of the company underlie the strategies of all levels (corporate strategy, business strategy, functional and operational strategies). The choice of the set of stakeholder engagement strategies is caused by the company's commitment to long-term balanced relationships with all its stakeholders, for that in the short term the company can deliberately commit the disturbance of the balanced relationships with any stakeholder. The selection of a particular strategy (to be more precisely, we should talk about the type of the strategy) of cooperation of the company with a particular stakeholder group is determined, on the one hand, by the results of the evaluation by the company of established relationships and possibilities for their changes, on the other hand, by the level of development of relevant competencies of the company (key competencies) required to implement each of the potential strategies.

For a certain period of time the stakeholder engagement plan of the company can change. Therefore, the practicality of the choice of any type of the engagement strategy with each stakeholder group can also change. It is not a new idea that the company shall use different strategies for cooperation with various stakeholders and, furthermore, different strategies with respect to the same stakeholder in different time (Jawahar \& McLaughlin, 2002). It is assumed that at different stages of the life cycle of the company required different resources, and thus the relative importance of each stakeholder and therefore the stakeholder engagement strategy shall change. As a result, an attempt is made at each stage of the company life cycle: establishment (creation), growth, maturity, revival (Miller \& Friesen, 1984; Drazin \& Kazanjian, 1990; Su et al., 2013; Gorshkova et al., 2014), to put into correspondence with each of the relevant stakeholders one of the four strategies: response, protection, adaptation and anticipation, proposed by Carroll, A. (1979).

In the study (Solodukhin, 2009) we proposed a set of types of stakeholder engagement strategies of the company: stakeholder satisfaction, protection, impact, cooperation.

The first type of the stakeholder engagement strategy (stakeholder satisfaction) is appropriate in the situation when a stakeholder is dissatisfied with resources received from the company, its expectations regarding the company are negative (the change in the situation for the better is not expected), and the possibility of its impact on the company (degree of power) is significantly higher than the company`s possibility to influence this stakeholder. In this case, the natural intention of the stakeholder shall be a change in relationships, i.e. redistribution of resource sharing (the ratio of quasi-rents obtained) in his lher favor. In the current situation the stakeholder has all the necessary tools to implement such changes. In this case the company has to focus on the satisfaction of the stakeholder, perhaps even to the detriment of other stakeholder groups. As an example may be given the interaction of the company with the client in the monopsonisctic market, notably in the situation when the customer is not satisfied and experiences negative expectations. Thus, the company faces a choice between the immediate satisfaction of the majority of client requests (even to the detriment of other stakeholders, such as owners, who shall receive less profit, or employees, who shall have to work much more for the same wages) and the loss of the business (which may lead to the liquidation of the entire company, if this business was the main or single for the company).

The second type of the stakeholder engagement strategy (protection) is appropriate in a similar situation, which differs only by the positive expectations of the stakeholder concerning the company. Either the expectations of the stakeholder in respect of the company are negative, but the stakeholder is satisfied with the current resource sharing. In this case, the stakeholder group may not long for urgent changes. Accordingly, the company can avoid the need for the full satisfaction of the stakeholder to the detriment of others. To do this, it can try to reduce the imbalance in the degree of mutual influence by organizing the coalition with other stakeholders and creating new leverage.

In the situation when the company is not satisfied with resources received from the stakeholder and the extent of its influence is greater than that of the stakeholder, the company can achieve the redistribution of resource sharing (the ratio of quasi-rents obtained) in its favor. In this case, whether the company tries to do it immediately or not, depends on its expectations. In this case, there is a third type of the stakeholder engagement strategy (impact). As an example, the relationships of the company with its employees in the event of a substantial increase in the number of clients (for example, by creating a unique product that has made of the company a monopoly). In this case, the company tries to change the terms of remuneration of the staff in its favor (with the exception, perhaps, of some key personnel).

Finally, when the relationships are balanced at all levels, changing the relationships (and the cost of resources for this purpose) becomes unprofitable for both the company and the stakeholder. In this case, we can talk about the 
strategies for "mutually beneficial cooperation" aimed at maintaining the balance. However, note that in long-term use of this type of strategies the stagnation in the relationships between the company and the stakeholder group (the ratio of quasi-rents is preserved, but the actual quasi-rents (their absolute values) do not grow). Therefore, in order to develop these relationships, the company shall periodically seek a slight shift in the characteristics of the relations in its favor.

Note that the strategies of different types may follow each other. For example, using the strategy of "stakeholder satisfaction", we can come to a situation when the application of the "protection" strategy becomes possible, and after some time the "cooperation" strategy also becomes possible. Applying an "impact" strategy is hardly possible for a long period of time, and it must also be replaced by the "cooperation" strategy.

In its content the anticipation strategy of Carroll A. is close to what we have called the "stakeholder satisfaction", and the adaptation strategy, in fact, means our "protection" strategy. At the same time, according to Carroll, the protection and response strategies in general cannot be called stakeholder engagement strategies, as they require ignoring requests of stakeholders (and even the fight against them for implementation of the response strategy) with the exception, perhaps, performing only the minimum required by law (for protection strategy). Following these two strategies, in fact, means that the company does not adhere to stakeholder management as a discrete institutional alternative (Tambovtsev, 2008a; Tambovtsev, 2008b).

In addition, these four types of strategies - a reactive strategy (while the impact and cooperation strategies proposed in the present study are proactive ones). In this regard the authors (Jawahar \& McLaughlin), recommending the choice of a certain stakeholder engagement strategy, link this choice neither with any company`s capabilities to follow this strategy (the presence of a set of necessary company`s competencies), nor with the already existing relationships between the company and the stakeholder group (mutual expectations, mutual intention to change the relations, the degree of mutual impact within the existing structure of formal and informal institutions). It should also be noted possible problems with the determination of the life cycle stage for some organizations, such as the institutions of higher education.

Previously, the authors have proposed the methods for selection of the type of stakeholder engagement strategies of the company with every important stakeholders within the same period (Solodukhin \& Gresko, 2013).

The present study solves the problem of the development of multi-period model for selection of the type of the stakeholder engagement strategy of the company.

\section{Methods}

In the previously developed methods of choosing the types of stakeholder engagement strategies of the company within the same period for each type of strategy, first of all there calculated the applicability of the strategy of $l$-type $(l=\overline{1,4})$ in respect of the $k$-stakeholder group $\left(w_{l}^{k}\right)$ using the following formulas:

$$
w_{1}^{k}=\frac{5+G_{1}^{k}-V^{k}}{20}, \quad w_{2}^{k}=\frac{10-\left|G_{1}^{k}-5\right|-V^{k}}{15}, w_{3}^{k}=\frac{5+G_{2}^{k}+V^{k}}{20}, w_{4}^{k}=\frac{25-G_{1}^{k}-G_{2}^{k}-\left|V^{k}\right|}{25},
$$

where $V^{k}$ - means the degree of mutual influence between the company and $k$ stakeholder group, $G_{1}^{k}-$ means the degree of intention of the $k$-stakeholder group to change the relationships with the company, $G_{2}^{k}-$ means the degree of intention of the company to change the relationships with the $k$-stakeholder group (Solodukhin, 2009).

The degree of intention to change the relationships can take values ranging from 0 to 10 , and, the higher the value is, the greater the intention to change the existing relationships with the counterparty in its own favor. The degree of mutual influence can vary from -5 to 5 . In this regard the positive values correspond to cases when the influence the company has on the stakeholder exceeds the potential influence the stakeholder has on the company (negative values - on the contrary). If the degree of influence the company has on the stakeholder group is approximately equal to the degree the stakeholder has on the company, the degree of mutual influence is taken to be zero.

It should be noted that one of the main problems associated with the assessment of the characteristics of relationships is that they are vague, fuzzy concepts the values of which are markedly affected by the judgment, perception and emotions of the expert. In addition, the assessment of relationships is much more difficult quantitatively than qualitatively (verbally). In this regard, for the quantitative measurement of relations can be used tools of fuzzy set theory (Zadeh, 1965; Zadeh, 1973; Zimmermann \& Zysno, 1983; Grubov, 2001).

In this case, the numerical values of the characteristics of relationships can be obtained as "centers of gravity" of the corresponding fuzzy sets. 
Hereafter the authors have proposed the methods for selection of stakeholder engagement strategies of the institution of higher education in the face of uncertainty, when the characteristics of the relationships between them are not exactly known and depend on the way the external environment changes.

At the increase of the planning time-frame the repeated (and not always monotonic) changes in the characteristics of relations shall be taken into account. This raises the need to develop a multi-period model for selection of stakeholder engagement strategies of the company.

Let there be $n$ scenarios of environmental change, in the result of which in each of $t$ periods in a certain way changed the relations between the institution of higher education and the $k$ stakeholder group. For each $j$ period $(j=\overline{1, t})$ the characteristics of relationships can be expertly evaluated and the coefficients of applicability of $l$-type of strategy in respect of $k$-stakeholder group $\left(w_{l i j}^{k}\right)$ within $i$ - scenario $(i=\overline{1, n})$ (Table 1).

Table 1. Coefficients of applicability of $l$-type of strategy in respect of $k$-stakeholder group

\begin{tabular}{ccclc}
\hline \multirow{2}{*}{ Scenarios } & \multicolumn{4}{c}{ Periods } \\
\cline { 2 - 5 } & Period 1 & Period 2 & $\ldots$ & Period $t$ \\
\hline Scenario No. 1 & $w_{l 11}^{k}$ & $w_{l 12}^{k}$ & $\ldots$ & $w_{l l t}^{k}$ \\
Scenario No. 2 & $w_{l 21}^{k}$ & $w_{l 22}^{k}$ & $\ldots$. & $w_{l 2 t}^{k}$ \\
$\ldots$. & $\ldots$. & $\ldots$. & $\ldots$ & $\ldots \ldots$ \\
Scenario $n$ & $\ldots w_{l n 1}^{k}$ & $w_{l n 2}^{k}$ & $\ldots$ & $w_{l n t}^{k}$ \\
\hline
\end{tabular}

Coefficients of applicability of $l$-type of strategy in respect of $k$-stakeholder group on each scenario can be reduced to a single integral coefficient $\left(w_{l i}^{k}\right)$ by the following formula:

$$
w_{l i}^{k}=\frac{\sum_{j=1}^{t} w_{l i j}^{k} \cdot q_{j}^{k}}{\sum_{j=1}^{t} q_{j}^{k}},
$$

where $t$ - means a number of periods, $i$ - means scenario number, $q_{j}^{k}$ - means the coefficient reflecting the degree of confidence of an expert (or a decision-maker (DM)) in the coefficient of applicability of $l$-type of strategy in respect of $k$-stakeholder group obtained for $j$-period.

It should be noted that the coefficients $q_{j}^{k}$ do not depend on $l$ (equal for all types of strategy for a given stakeholder and a specific period), as they reflect the degree of certainty of the expert that in this period the relationships with certain characteristics shall be developed between the company and the stakeholder. In turn, the coefficients of applicability of all types of stakeholder engagement strategies are calculated through the relationships with the same characteristics.

It can be assumed that $q_{j}^{k} \geq q_{j+1}^{k}$, as in the more remote periods the expert (or DM) shall have a little understanding of the factors determining the relationships between the company and the stakeholder group, and, therefore, less confidence in the applicability of a particular type of stakeholder engagement strategies.

Coefficients $q_{j}^{k}$ can also reflect the risk tolerance of the decision-maker. The decision-maker with a high degree of risk tolerance may try to "win" by virtue of future prediction and that he shall choose a relevant type of strategy.

On Figure 1 the dynamics of $q_{j}^{k}$ decay for the decision-maker with high and low risk tolerance have schematically been showed.

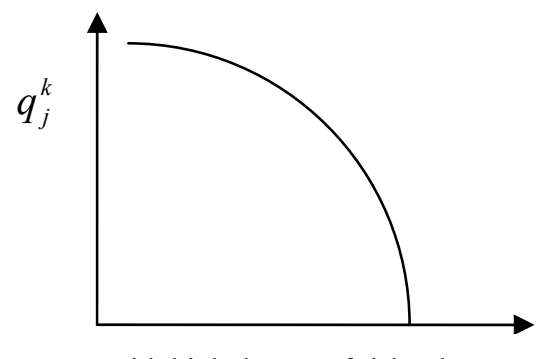

DM with high degree of risk tolerance

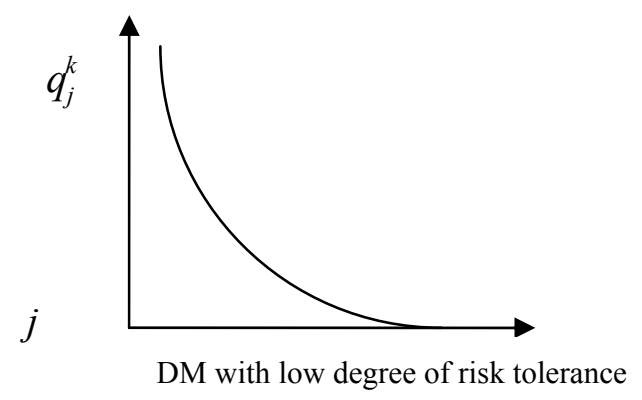

DM with low degree of risk tolerance

Figure 1. The dynamics of $q_{j}^{\kappa}$ decay for the decision-maker (DM) with various degrees of risk tolerance 
It should be noted that the degree of the certainty of the expert (or DM) in the information about the relationships between the company and the stakeholder group for $j$-period, as well as risk tolerance, can change in various scenarios. In this case the formula (2) can be modified as follows:

$$
w_{l i}^{k}=\frac{\sum_{j=1}^{t} w_{l i j}^{k} \cdot q_{i j}^{k}}{\sum_{j=1}^{t} q_{i j}^{k}},
$$

where $q_{i j}^{k}$ - means the coefficient reflecting the certainty of the expert (or DM) in applicability coefficient of $l$-type of strategy within $i$-scenario for $j$-period.

Accordingly, the dynamics of $q_{i j}^{k}$ decay within various scenarios may differ essentially.

\section{Results}

Let us consider the process of selecting the type of stakeholder engagement strategy by the example of the Vladivostok State University of Economics and Service (VSUES) and its stakeholder group "Employees". The selection of the stakeholder engagement strategy in relations between the University and this stakeholder group is especially difficult, as the employees at the same time act both as a significant stakeholder of the university and as its most important resource (Solodukhin, 2009).

Table 2. Characteristics of relationships and weighing coefficients of applicability of types of stakeholder engagement strategies for the first scenario

\begin{tabular}{|c|c|c|c|c|}
\hline \multicolumn{5}{|c|}{ Scenario No. 1} \\
\hline \multirow{2}{*}{$\begin{array}{l}\text { Characteristics of relationships and weighing } \\
\text { coefficients of applicability of types of stakeholder } \\
\text { engagement strategies }\end{array}$} & \multicolumn{4}{|c|}{ Periods } \\
\hline & 2014 & $2015-2016$ & 2017-2018 & 2018-2019 \\
\hline \multicolumn{5}{|l|}{ Characteristics of relationships: } \\
\hline Degree of mutual influence & 2 & 2 & 3 & 4 \\
\hline $\begin{array}{l}\text { Degree of intention of the stakeholder group to } \\
\text { change the relationships with the university }\end{array}$ & 3.5 & 4 & 4 & 4 \\
\hline $\begin{array}{l}\text { Degree of intention of the university to change the } \\
\text { relationships with the stakeholder group }\end{array}$ & 5 & 5 & 6 & 8 \\
\hline \multicolumn{5}{|l|}{$\begin{array}{l}\text { Weighing coefficients of applicability of types } \\
\text { of strategies: }\end{array}$} \\
\hline Stakeholder satisfaction & 0.35 & 0.35 & 0.3 & 0.25 \\
\hline Protection & 0.47 & 0.47 & 0.4 & 0.33 \\
\hline Impact & 0.6 & 0.6 & 0.7 & 0.85 \\
\hline Cooperation & 0.56 & 0.56 & 0.48 & 0.36 \\
\hline
\end{tabular}

Table 3. Characteristics of relationships and weighing coefficients of applicability of types of stakeholder engagement strategies for the second scenario

\begin{tabular}{|c|c|c|c|c|}
\hline \multicolumn{5}{|c|}{ Scenario No. 2} \\
\hline \multirow{2}{*}{$\begin{array}{l}\text { Characteristics of relationships and weighing } \\
\text { coefficients of applicability of types of stakeholder } \\
\text { engagement strategies }\end{array}$} & \multicolumn{4}{|c|}{ Periods } \\
\hline & 2014 & 2015-2016 & 2017-2018 & 2018-2019 \\
\hline Characteristics of relationships: & & & & \\
\hline Degree of mutual influence & 2 & 2 & 1 & 2 \\
\hline $\begin{array}{l}\text { Degree of intention of the stakeholder group to } \\
\text { change the relationships with the university }\end{array}$ & 3.5 & 4 & 7 & 6 \\
\hline $\begin{array}{l}\text { Degree of intention of the university to change the } \\
\text { relationships with the stakeholder group } \\
\text { Weighing coefficients of applicability of types } \\
\text { of strategies: }\end{array}$ & 5 & 5 & 3 & 5 \\
\hline Stakeholder satisfaction & 0.35 & 0.35 & 0.55 & 0.45 \\
\hline Protection & 0.47 & 0.47 & 0.47 & 0.47 \\
\hline Impact & 0.6 & 0.6 & 0.45 & 0.6 \\
\hline Cooperation & 0.56 & 0.56 & 0.56 & 0.48 \\
\hline
\end{tabular}


Table 4. Characteristics of relationships and weighing coefficients of applicability of types of stakeholder engagement strategies for the third scenario

\begin{tabular}{|c|c|c|c|c|}
\hline \multicolumn{5}{|c|}{ Scenario No. 3} \\
\hline \multirow{2}{*}{$\begin{array}{l}\text { Characteristics of relationships and weighing } \\
\text { coefficients of applicability of types of stakeholder } \\
\text { engagement strategies }\end{array}$} & \multicolumn{4}{|c|}{ Periods } \\
\hline & 2014 & 2015-2016 & 2017-2018 & 2018-2019 \\
\hline \multicolumn{5}{|l|}{ Characteristics of relationships: } \\
\hline Degree of mutual influence & 2 & 2 & 1 & 0 \\
\hline $\begin{array}{l}\text { Degree of intention of the stakeholder group to } \\
\text { change the relationships with the university }\end{array}$ & 3.5 & 5 & 7 & 8 \\
\hline $\begin{array}{l}\text { Degree of intention of the university to change the } \\
\text { relationships with the stakeholder group }\end{array}$ & 5 & 5 & 6 & 6 \\
\hline \multicolumn{5}{|l|}{$\begin{array}{l}\text { Weighing coefficients of applicability of types } \\
\text { of strategies: }\end{array}$} \\
\hline Stakeholder satisfaction & 0.35 & 0.4 & 0.55 & 0.65 \\
\hline Protection & 0.47 & 0.53 & 0.47 & 0.47 \\
\hline Impact & 0.6 & 0.6 & 0.6 & 0.55 \\
\hline Cooperation & 0.56 & 0.52 & 0.44 & 0.44 \\
\hline
\end{tabular}

Then considered three scenarios of a change in the relations between them for three time periods (each period lasts for two years). Initially, for each scenario based on the characteristics of the relationships by the formulas (1) weighing coefficients of applicability of each type of strategy are calculated. Tables 2, 3, 4 contain quantitative estimates of the characteristics of relationships and weighing coefficients of applicability of types of stakeholder engagement strategies for three scenarios for each period as of the current date.

Pro forma quantitative evaluation of characteristics of the relationships for three periods corresponds to the qualitative content of each scenario.

The first scenario assumes a gradual increase in the degree of influence of the university on the stakeholder group "Employees" as a result of the planned reduction in the number of public institutions of higher education and their branches and increased competition for workplaces in the remaining educational institutions. At the same time, due to the increasing demands of employers to the quality of the educational process and the results of scientific activities, there shall increase the requirements of universities to its employees, especially to their characteristics (professional experience, skill level, reputation in the scientific community, etc.) determining the quality and quantity of resources obtained from them. Accordingly, over time the degree of intention of the university to change the relations with this stakeholder group shall increase. The degree of intention of employees to change the relations with the university shall remain at the same level as ensured a faster growth of salaries of employees of the university compared to the average salary in the economy of the region. At the same time the comfort of working conditions and social security remain at a high level.

The second scenario assumes updating of the qualitative composition of the university staff, as on the one hand, some of the staff cannot meet the increased requirements, on the other hand, betting on a practice-oriented teaching, the university shall be interested in attracting the qualified staff with experience in the business environment. In this case, the degree of intention of a given stakeholder group to change the relations with the university will gradually increase as new highly qualified staff will be interested not only in high salaries and decent material and technical base, but also in the acquisition of other resources, primarily in the qualitative organizational and management processes. The degree of influence of the university with respect to such employees will not grow and may even decrease slightly.

The third scenario assumes a radical updating of the qualitative composition of the university staff. The reason for this may be a tougher competitive pressure on the university while tightening the requirements of the other stakeholders. In these circumstances, the university shall have to put much more ambitious targets for the achievement of which there will be a need for the relevant staff. Under this scenario, the degree of influence of the university with respect to the stakeholder group will fall, reaching a state when the mutual influence of the university and the stakeholder group will be balanced. The pace of change in the other characteristics of the relations will obviously be higher than in the second scenario.

It should be noted that in reality the number of scenarios under consideration can be greater (for example, it may be considered the different rates of reduction in the number of universities). In this example, we are limited to three scenarios for reasons of clarity and easy perception of models. 
The next step is to expertly determine the coefficients $q_{i j}^{k}$ (Table 5).

Table 5. Coefficients $q_{i j}^{k}$

\begin{tabular}{cccc}
\hline \multirow{2}{*}{ Scenario (probability points) } & \multicolumn{3}{c}{ Periods } \\
\cline { 2 - 4 } & $2015-2016$ & $2017-2018$ & $2018-2019$ \\
\hline Scenario No. 1 $(0.2)$ & 0.8 & 0.7 & 0.6 \\
Scenario No. 2 $(0.5)$ & 0.7 & 0.6 & 0.5 \\
Scenario No. 3 $(0.3)$ & 0.9 & 0.8 & 0.4 \\
\hline
\end{tabular}

Then according to the formula (3) calculated the integral coefficients for which for each type of strategy calculated the mathematical expectation indicators and mean squared deviation (Table 6).

Table 6. Integral coefficients of applicability of types of stakeholder engagement strategies

\begin{tabular}{ccccc}
\hline \multirow{2}{*}{ Scenario (probability points) } & \multicolumn{3}{c}{ Types of stakeholder engagement strategies } \\
\cline { 2 - 5 } & $\begin{array}{c}\text { Stakeholder } \\
\text { satisfaction }\end{array}$ & Protection & Impact & Cooperation \\
\hline Scenario No. 1 (0.2) & 0.3 & 0.41 & 0.7 & 0.48 \\
Scenario No. 2 (0.5) & 0.44 & 0.47 & 0.55 & 0.54 \\
Scenario No. 3 (0.3) & 0.5 & 0.49 & 0.59 & 0.47 \\
Mathematical expectation & 0.43 & 0.46 & 0.59 & 0.51 \\
Mean squared deviation & 0.061 & 0.031 & 0.059 & 0.032 \\
\hline
\end{tabular}

In order to choose the most appropriate type of stakeholder engagement strategies, firstly we use the method for selection of stakeholder engagement strategies of the university on the basis of a generalized criterion. Let us consider the two-criteria optimization problem, where the partial criteria are the mathematical expectation and mean squared deviation. In the study (Rosen, 2002) for solving this problem it is proposed to use the generalized criterion, which is a weighted sum of partial criteria of the mathematical expectation and mean squared deviation with weighing coefficients 1 and -[lambda]:

$$
k(E, \sigma)=E-\lambda \sigma
$$

where $\lambda$ - means some constant, $E$ - means mathematical expectation, $\sigma$ - means mean squared deviation.

The value [lambda] characterizes the risk tolerance of the decision-maker. If the value [lambda] is greater than zero, the decision-maker is not inclined to take risks, as in this case the estimate of the random variable obtained by the generalized criterion, is less than its mean value that characterizes a reasonably prudent person. If the value [lambda] is less than zero, it is another situation that means the decision-maker is inclined to take risks. Finally if [lambda] is equal to zero, the decision-maker is indifferent to risk, since the estimate (4) of the random variable is equal to its mean value.

As can be seen from Table 6 by the ratio of the mathematical expectation and mean squared deviation, satisfaction strategy $(S)$ can be excluded from further consideration, since the other strategies exceed this strategy according to Pareto. Cooperation $(C)$, impact $(I)$ and protection $(P)$ strategies are incomparable according to Pareto. Narrowing of the Pareto-optimal set can be made only if there is an additional information about the ratio of the criteria of mathematical expectation and mean squared deviation.

In order to establish the ranking of the Pareto-optimal set $(C, I, P)$ under the generalized criterion it is necessary to determine the lower limit of the risk aversion and the upper limit of the risk aversion by the following formulas:

$$
\lambda^{0}=\min \left\{\frac{E_{i_{1}}-E_{i_{2}}}{\sigma_{i_{1}}-\sigma_{i_{2}}}\right\}, \lambda^{*}=\max \left\{\frac{E_{i_{1}}-E_{i_{2}}}{\sigma_{i_{1}}-\sigma_{i_{2}}}\right\},
$$

where $\lambda^{0}$ - means the lower limit of the risk aversion, $\lambda^{*}$ - means the upper limit of the risk aversion, $\left(E_{i_{1}}, \sigma_{i_{1}}\right)$ and $\left(E_{i_{2}}, \sigma_{i_{2}}\right)$ - means the mathematical expectation and mean squared deviation of two fixed alternatives $a_{i_{1}}$ and $a_{i_{2}}$; such operators as min and max can be applied to such pairs of indexes as $\left(i_{1}, i_{2}\right)$, for which the alternatives $a_{i_{1}}, a_{i_{2}}$ are Pareto optimal. Provided that $E_{i 1}>E_{i 2}$ and $\sigma_{i 1}>\sigma_{i 2}$. 
Thus we obtain: $\frac{E_{I}-E_{C}}{\sigma_{I}-\sigma_{C}}=\frac{0.59-0.51}{0.059-0.032} \approx 3.2, \frac{E_{C}-E_{P}}{\sigma_{C}-\sigma_{P}}=\frac{0.51-0.46}{0.032-0.031} \approx 113, \frac{E_{I}-E_{P}}{\sigma_{I}-\sigma_{P}}=\frac{0.59-0.46}{0.059-0.031} \approx 4.7$

It follows that: $\lambda^{0}=\min \{3.2 ; 113 ; 4.7\}=3,2, \lambda^{*}=\max \{3.2 ; 113 ; 4.7\}=113$.

Thus, the interval $(0,+\infty)$ can be divided into three intervals: $(0 ; 3.2)$ - the area of low risk aversion (the area of low cautiousness); $(3.2 ; 113)$ - the area of uncertainty; $(113 ;+\infty)$ - the area of high risk aversion (the area of high cautiousness).

If the decision-maker has the risk aversion of the following value: $0 \leq \lambda<3.2$, then ranking of the Pareto-optimal alternatives coincides with their ranking by the value of expected payoff: $I \succ C \succ P$ (the symbol $\succ$ denotes the preference by the value of the generalized criterion). In this case, the optimal strategy will be an impact strategy.

If the decision-maker has the risk aversion of the following value: $\lambda>113$, then ranking of the Pareto-optimal alternatives coincides with their ranking by the risk indicator: $P \succ C \succ I$. In this case, the optimal strategy will be a protection strategy.

Let us consider the case when the risk aversion of the decision-maker gets into the area of uncertainty. Let's take, for example, $\lambda=10$. Then $k(C)=0.51-0.032 \cdot 10 \approx 0.19 ; k(P)=0.46-0.031 \cdot 10 \approx 0.15 ; k(I)=0.59-0.059 \cdot 10 \approx 0$. Then we obtain the following ranking: $C \succ P \succ I$. Thus, in this case the preference for the pair $(P, I)$ is determined by the value of the expected payoff, while for the pair $(P, C)$ - by the risk value.

Then let's consider for the same example the method of selection of stakeholder engagement strategies of the company on the basis of the expected utility criterion.

Firstly we introduce some definitions. Let us consider the random variable: $\xi=\left[\begin{array}{l}x_{1} \ldots x_{k} \\ p_{1} \ldots p_{k}\end{array}\right]$, where $p_{i} \geq 0$, $\sum_{i=1}^{k} p_{i}=1$ as a winning lottery with payoffs $x_{1}, \ldots, x_{k}$, where $p_{i}$ - means the share of lottery tickets with

payoffs: $x_{i} \quad(i=\overline{1, k})$. In our case, since in selection of the type of strategy the decision-maker does not know under what scenario the relationships of the company with the stakeholder group shall be built up, then let the types of stakeholder engagement strategies be the lotteries. Under $x_{i}$ and $p_{i}$ we shall consider the applicability of types of strategies and probability points of scenarios, respectively.

Thus, let us consider four types of strategy (lottery): $\xi_{1}=\left[\begin{array}{ccc}0.3 & 0.44 & 0.5 \\ 0.2 & 0.5 & 0.3\end{array}\right], \quad \xi_{2}=\left[\begin{array}{ccc}0.41 & 0.47 & 0.49 \\ 0.2 & 0.5 & 0.3\end{array}\right]$, $\xi_{3}=\left[\begin{array}{ccc}0.7 & 0.55 & 0.59 \\ 0.2 & 0.5 & 0.3\end{array}\right], \quad \xi_{4}=\left[\begin{array}{ccc}0.48 & 0.54 & 0.47 \\ 0.2 & 0.5 & 0.3\end{array}\right]$. For the selection of the most suitable type of stakeholder engagement

strategy it is necessary to identify a deterministic equivalent (DE) for each type of strategy. The deterministic equivalent of the type of stakeholder engagement strategy shall be the applicability of the type of strategy at absolutely probable scenario ( $p=1$ ), which for the decision-maker is equivalent (equal to) the adoption of this type of stakeholder engagement strategies in the face of uncertainty (it means that the decision-maker does not know under what scenario the relationships of the company with the stakeholder group shall be built up). The selection will be done by the decision-maker in favor of such type of stakeholder engagement strategy, which shall correspond to the highest deterministic equivalent.

In order to determine the deterministic equivalent of the type of stakeholder engagement strategy, the following algorithm can be used (Rosen, 2002):

Step 1. Under a given type of stakeholder engagement strategy $\xi$ construct the type of stakeholder engagement strategy according to utility criterion $u[\xi]$. For that it is necessary in the type of stakeholder engagement strategy $\xi$ to replace each case of applicability of the type of stakeholder engagement strategy $x_{i}$ on its utility $u\left(x_{i}\right)$.

Step 2. Find the expected utility $E(u[\xi])$ of the type of stakeholder engagement strategy $\xi$ by the following formula:

$$
E(u[\xi])=\sum_{i=1}^{k} p_{i} u\left(x_{i}\right)
$$


Step 3. From the point $E(u[\xi])$ on the y-axis "move" through the curve of equivalents onto the x-axis. The resulting point $u^{-1}(E(u[\xi])$ ) shall be the deterministic equivalent of the type of stakeholder engagement strategies.

Firstly let us construct the curve of equivalents of the types of stakeholder engagement strategies, applicability of which is between the values 0.3 and 0.7 (between the worst and the best values of the applicability of the types of stakeholder engagement strategies).

In order to construct the given curve it is necessary to find five points $(a ; 0),(A ; 1),\left(x_{0.25} ; 0.25\right),\left(x_{0.5} ; 0.5\right),\left(x_{0.5} ; 0.75\right)$, provided that the last three points shall be found by questioning the decision-maker. It should also be noted that in this case $a$-means the worst value of applicability of the types of stakeholder engagement strategies; $A-$ means the best value of applicability of the types of stakeholder engagement strategies; $a<x_{0.25}<x_{0.5} ; x_{0.5}<$ $x_{0.75}<A$. The scientific work (Rosen, 2002) also proposes the use of one more additional limitation: $a<x_{0.5}<$ $E \xi_{0.5}$. In the implementation of this limitation the curve of equivalents shall be convex, i.e. the decision-maker is not inclined to take risks.

Questioning of the decision-maker shall be carried out in the following form. For example, in order to find the point $\left(x_{0.5} ; 0.5\right)$ the decision-maker shall be asked the following question:

"What should be the applicability of the type of stakeholder engagement strategy at utility level equal to 0.5 ?". The questions about how to find the points $\left(x_{0.25} ; 0.25\right)$ and $\left(x_{0.75} ; 0.75\right)$ are asked in a similar manner. After finding five points, a smooth curve - an empirical curve of equivalents - is passed through these points (Figure 2).

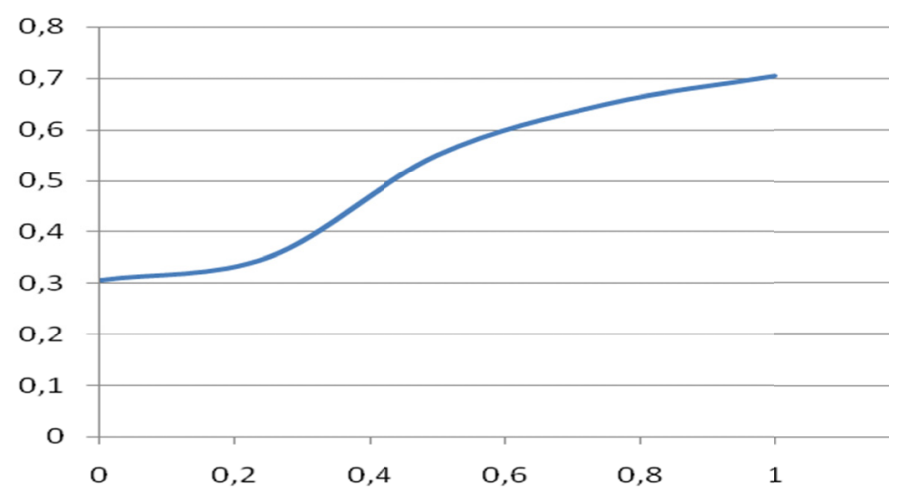

Figure 2. Empirical curve of equivalents

Let us determine step by step the deterministic equivalent of each type of stakeholder engagement strategy:

Step 1. $u\left[\xi_{1}\right] \approx\left[\begin{array}{ccc}0 & 0.49 & 0.55 \\ 0.2 & 0.5 & 0.3\end{array}\right], u\left[\xi_{2}\right] \approx\left[\begin{array}{ccc}0.45 & 0.51 & 0.55 \\ 0.2 & 0.5 & 0.3\end{array}\right], u\left[\xi_{3}\right] \approx\left[\begin{array}{ccc}1 & 0.58 & 0.59 \\ 0.2 & 0.5 & 0.3\end{array}\right], u\left[\xi_{4}\right] \approx\left[\begin{array}{ccc}0.52 & 0.57 & 0.52 \\ 0.2 & 0.5 & 0.3\end{array}\right]$.

Step 2. $E\left(u\left[\xi_{1}\right]\right)=0 * 0.2+0.49 * 0.5+0.55 * 0.3=0.41, \quad E\left(u\left[\xi_{2}\right]\right)=0.51, \quad E\left(u\left[\xi_{3}\right]\right)=0.67, \quad E\left(u\left[\xi_{4}\right]\right)=0.55$.

Step 3. $D E \xi_{1}=u^{-1}\left(E\left(u\left[\xi_{1}\right]\right)\right)=u^{-1}(0.41) \approx 0.38, \quad D E \quad \xi_{2}=u^{-1}\left(E\left(u\left[\xi_{2}\right]\right)\right)=u^{-1}(0.51) \approx 0.47$, $D E \xi_{3}=u^{-1}\left(E\left(u\left[\xi_{3}\right]\right)\right)=u^{-1}(0.667) \approx 0.82, D E \quad \xi_{4}=u^{-1}\left(E\left(u\left[\xi_{4}\right]\right)\right)=u^{-1}(0.545) \approx 0.57$.

\section{Discussions}

The highest deterministic equivalent has been obtained for the strategy $\xi_{3}$ (the impact strategy). Thus, by the expected utility criterion, this type of stakeholder engagement strategy is the most preferred. In this case, the selection of the most preferred type of strategy based on the expected utility criterion (in terms of the deterministic equivalent) coincides with the selection of the most preferred type of strategy based on the criterion of the expected payoff (in terms of the mathematical expectation). Thus, the selection of a particular strategy of the university in respect of the stakeholder group "Employees" in the framework of this type must be somehow related to the redistribution of resource sharing (the ratio of quasi-rents obtained) in the company's favor with the help of various tools of influence. The development of the situation (internal and external conditions) under a particular scenario shall undoubtedly lead to an adjustment of the adopted strategy. Thus it is necessary to keep track of changes in the characteristics of relations, as their significant changes can cause a substantial revision of the strategy (the transition to a different type of strategy). 
It should be noted that in general case of making a decision on the selection of the preferred type the strategies may vary. In this case, the final decision shall be made by the decision-maker with regard to such non-programmed criteria as experience, intuition, etc.

\section{Conclusions}

The proposed multi-period model for selection of stakeholder engagement strategies of the company allows to evaluate the applicability of each type of strategy, depending on the possible changes in the relationships between the company and each stakeholder group. In this case, when deciding on the most appropriate type of strategy the attitude of the decision-maker to taking risks is taken into account. At the same time there remains an open question of the selection of the most preferred type of strategy in case if the decision on the basis of the generalized criterion is contrary to the decision on the basis of the deterministic equivalent. Perhaps in the future there will be proposed a formal procedure of selection for such cases. Besides from now forward it is expected to develop a method of using the mixed strategies as a way to reduce the risk in the cooperation of the company with the stakeholder groups. Another promising direction of research in this area is to develop models that take into account the changes in the characteristics of relationships between the stakeholders, since the changes in these relationships undoubtedly affect the relationships of stakeholders with the company (with a certain delay).

In our experience, the use of such formal models of selection strategies for engaging the organization with stakeholders is the most appropriate for decision-makers with a relatively moderate risk appetite. Decision-making by managers with a very high or, conversely, very low risk appetite is largely dependent on behavioral factors.

\section{References}

Carroll, A. (1979). A three dimensional conceptual model of corporate social performance. Academy of Management Review, 4(4), 497-505. http://dx.doi.org/10.2307/257850

Dietrich, M., \& Krafft, J. (2012). Handbook on the Economics and Theory of the Firm. Cheltenham. Edward Elgar Publishing. http://dx.doi.org/10.4337/9781781002407

Drazin, R., \& Kazanjian, R. (1990). A reanalysis of Miller and Friesen's life cycle data. Strategic Management Journal, 11(4), 319-325. http://dx.doi.org/10.1002/smj.4250110407

Foss, N., Lando, H., \& Thomsen, S. (1998). The theory of the firm. In B. Bouckaert, \& G. De Geest (Eds.). Encyclopedia of Law \& Economics, 631-658.

Freeman, R. (1984). Strategic management: A stakeholder approach. Boston: Pitman Publishing.

Gorshkova, L. A., Trifonov, Y. V., \& Poplavskaya V. A. (2014). Ensuring adaptability of a company using life cycle theory. Life Science Journal, 11(10), 705-708.

Grubov, E. (2001). Development of the decision support system in the institution of higher education based on the theory of fuzzy sets. $\mathrm{PhD}$ thesis in Economics, Ivanovo.

Jawahar, I., \& McLaughlin, G. (2002). Toward a descriptive stakeholder theory: An organizational life cycle approach. Academy of Management Review, 26(3), 397-414. http://dx.doi.org/10.5465/amr.2001.4845803

Kleiner, G. (1999). Russian economy and the crisis of mutual expectations. Social Sciences and Modernity, 2, 5-19.

Kleiner, G. (2003a, September 25-27). Evolution and modernization of the theory of the firm. Economic Transformation and Evolutionary Theory of J. Schumpeter. The $5^{\text {th }}$ International Symposium on Evolutionary Economics. Pushchino. Moscow: Institute of Economics of the Russian Academy of Sciences.

Kleiner, G. (2003b). From the business theory to the strategic management theory. Russian Management Journal, $1,31-56$.

Kleiner, G. (2008). Business strategy. Moscow: Case Publishing.

Miller, D., \& Friesen, P. (1984). A longitudinal study of the corporate life cycle. Management Science, 30(10), 1161-1183. http://dx.doi.org/10.1287/mnsc.30.10.1161

Phillips, R. (Ed.). (2011). Stakeholder Theory: Impact and Prospects. Cheltenham. Edward Elgar Publishing. http://dx.doi.org/10.4337/9780857936349

Post, J., Preston, L., \& Sachs, S. (2002). Redefining the Corporation: Stakeholder Management and Organizational Wealth. Stanford: Stanford University Press. http://dx.doi.org/10.5860/choice.40-3511

Rosen, V. (2002). Mathematical models of decision-making in the economy: educational guidance. Moscow: 
University Publishing House. Higher School.

Solodukhin, K. (2009). Strategic management of the institution of the higher education as a stakeholder-company. Saint-Petersburg: Polytechnic University Publishing House.

Solodukhin, K., \& Gresko, A. (2013). Using expected utility criterion for choosing strategies of interaction of university with stakeholders. World Applied Sciences Journal, 27(7), 840-844.

Su, S., Baird, K., \& Schoch, H. (2013) Management control systems from an organisational life cycle perspective: The role of input, behaviour and output controls. Journal of Management \& Organization, 19, 635-658. http://dx.doi.org/10.1017/jmo.2014.7

Tambovtsev, V. (2008a). The legitimacy of the large property in Russia: institutional analysis and institutional design. Moscow: Book and Business, JSC.

Tambovtsev, V. (2008b). Stakeholder theory of the firm in the light of the concept of property regimes. Russian Management Journal, 6, 3-26.

Tambovtsev, V. (2010). Strategic Theory of the Firm: status and possible development. Russian Management Journal, 8(1), 5-40.

Zadeh, L. (1965). Fuzzy Sets. Information and Control, 8, 338-353. http://dx.doi.org/10.1016/s0019-9958(65) 90241-x

Zadeh, L. (1973). Outline of a New Approach to the Analysis of Complex Systems and Decision Processes. IEEE Trans. Sys. Man. Cybern., SMC-3, 28-44. http://dx.doi.org/10.1109/tsmc.1973.5408575

Zimmermann, H., \& Zysno, P. (1983). Decision Analysis and Evaluation by Hierarchical Aggregation of Information. Fuzzy Sets and Systems, 10, 243-266. http://dx.doi.org/10.1016/s0165-0114(83)80118-3

\section{Copyrights}

Copyright for this article is retained by the author(s), with first publication rights granted to the journal.

This is an open-access article distributed under the terms and conditions of the Creative Commons Attribution license (http://creativecommons.org/licenses/by/3.0/). 